\title{
Возможности современной лазерной литографии для синтеза микро- и наноструктурированных планарных оптических элементов
}

\author{
В.П. Корольков ${ }^{*}$ А.Г. Седухин, Р.К. Насыров, Р.В. Шиманский, \\ В.Н. Хомутов, А.Е. Качкин, А.Е. Маточкин \\ Институт автоматики и электрометрии СО РАН \\ *E-mail: korolkov@iae.nsk.su
}

DOI: 10.31868/RFL2020.168-169

В свете многочисленных современных публикаций по разработке и исследованию новых приборов и систем дифракционной и интегральной оптики, которые базируются на элементах с тонкослойными микро- и наноструктурами достаточно актуальным остается совершенствование технологической базы для создания названных элементов. Необходимо отметить, что, в силу большей простоты изготовления и технологического контроля качества, наиболее массовыми и доступными (по своей стоимости) продолжают оставаться планарные оптические элементы на поверхности которых формируется не только традиционные дифракционные и растровые компьютерно-синтезированные микро- и нано-структуры, но и структуры, относимые к области метаматериалов.

В докладе обсуждается состояние разработок и апробации двух сканирующих лазерных нанолитографов, которые были созданы в Институте автоматики и электрометрии (ИАиЭ) СО РАН, в рамках проекта РНФ «Развитие сверхразрешающей термохимической лазерной технологии формирования компьютерно-синтезированных дифракционных наноструктур». Данные установки ориентированы на использование именно планарных стеклянных подложек и безрезистной технологии прямой записи остросфокусированным лазерным лучом по тонким пленкам металлов. Дополнительно проводится сопоставление указанных установок с современной коммерческой установкой DWL66+ HiRes [1], которая также ориентирована на использование планарных подложек, но базируется на применении фоторезистов для изготовления как бинарных так и многоуровневых микроструктурированных оптических элементов. Последняя установка была закуплена в рамках гранта ФЦП на модернизацию оборудования ЦКП «Спектроскопия и оптика» совместно с другими технологическими средствами и аналитическим оборудованием.

Следует отметить, что несмотря на то, что разработанные в ИАиЭ нанолитографы прошли первые тестовые испытания, они продолжают совершенствоваться, в части дальнейшей модернизации отдельных узлов для повышения разрешающей способности лазерной записи, стабильности позиционирования лазерного луча по полю записи, а также отработки программного обеспечения и технологических режимов лазерной записи. Для сопоставления, ниже приводятся краткие характеристики установок.

Первый, компактный и относительно простой, нанолитограф, разработанный в ИАиЭ СО РАН [2], работает в прямоугольной системе координат XY и осуществляет лазерную запись произвольных планарных структур на пленках металлов типа $\mathrm{Cr}, \mathrm{Ti}, \mathrm{Zr}, \mathrm{Ta}, \mathrm{V}$, Mo, на поле размером $50 \times 50$ мм, с дискретностью измерения координат \pm 1 нм и с предельным пространственным разрешением порядка $350-450$ нм (зависит от материалов и режимов записи). В данной установке используется мощный диодный лазер с 
длиной волны 405 нм и возможностью аналоговой и импульсной модуляции. Установка способна обеспечить запись структур в непрерывном и импульсном режиме (с длительностью импульсов до 100 нс). Открытый модульный принцип построения и использование преимущественно стандартных узлов, позволяет проводить эксперименты по модернизации и исследованию новых узлов (фокусирующих систем, датчиков автофокусировки, приводов позиционирования луча и др.).

Второй, более сложный и крупногабаритный нанолитограф, разработанный в ИАиЭ СО РАН, работает в полярной системе координат $\mathrm{R} \varphi$ и осуществляет лазерную запись произвольных планарных структур на тех же указанных пленках металлов, на поле диаметром до 189 мм, с дискретностью позиционирования лазерного луча \pm 1 нм и с расчетным пространственным разрешением порядка 380 -500 нм. Установка спроектирована с двумя каналами записи с длиной волны 532 и 266 нм. В части модернизации узлов, установка менее гибкая, чем предыдущая, но обеспечивает существенно более скоростную запись до $10 \mathrm{~m} / \mathrm{c}$, на поле диаметром до 189 мм.

Наконец, последний коммерческий нанолитограф DWL66+ HiRes работает в режиме XY-позиционирования лазерного луча и его векторного перемещения на поле размером 200×200 мм. Здесь используется полупроводниковый лазер с длиной волны 375 нм. Дискретность позиционирования лазерного пятна составляет 5 нм при диаметре пятна 300 нм. Установка позволяет осуществлять запись как бинарных, так и многоуровневых микро- и нано-структур произвольной топологии.

Тестовые структуры, записанные на пленках металлов типа $\mathrm{Cr}, \mathrm{Ti}, \mathrm{Zr}, \mathrm{Ta}, \mathrm{V}$, Мо с помощью установок разработки ИАиЭ СО РАН продемонстрировали достаточные для многих практических задач результаты и позволили выявить более предпочтительные для записи металлы (в зависимости от требуемых характеристик, это $\mathrm{Cr}, \mathrm{Zr}$ и $\mathrm{Ti}$ ), а также новые режимы записи - в частности, режимы, обеспечивающие сквозное окисление пленок Ті. При оценке качества записи, учитывались такие параметры, как разрешающая способность, контраст записи, интегральная и локальная неровность краев формируемых дорожек (физическая ширина вследствие проявления пороговых свойств записи), пористость окисленных пленок и склонность к образованию микрокристаллитов, максимально допустимая скорость записи и другие. Был выявлен эффект сверхразрешения на пленках Zr, который позволил записывать регулярные решетки с периодом, равным шагу между треками при записи (в эксперименте, шаг составлял 250 нм, при диаметре светового пятна порядка 800 нм).

Данная работа была проведена при финансовой поддержке гранта РНФ № 17-1901721-П и при использовании оборудования ЦКП «Спектроскопия и оптика».

\section{Литература}

[1] https://heidelberg-instruments.com/en/products/dwl-66.html, выпуск 2019 года.

[2] В.П. Корольков, А.Г. Седухин, и др., Интерэкспо Гео-Сибирь. Национальная конференция с международным участием "СИБОПТИКА-2019". - 2019. — Т. 8. — С. 28-33. 